Revista Brasil. Bot., V.34, n.2, p.145-158, abr.-jun. 2011

\title{
Dinâmica do componente arbóreo de uma mata de galeria inundável (Brasília, Distrito Federal) em um período de oito anos
}

\author{
CLARISSA GOUVEIA FONTES ${ }^{1}$ e BRUNO MACHADO TELES WALTER ${ }^{2,3}$
}

(recebido: 20 de maio de 2009; aceito: 24 de fevereiro de 2011)

\begin{abstract}
Dynamics of the arboreal component in a swamp gallery forest (Brasília, Federal District) over an eight year period). Gallery forests play an important role in supporting the water resources and biodiversity of the Brazilian Central Plateau, but they have been under strong anthropic impact. Those that occur in poorly drained soils are little studied, with negative consequences for their conservation. The aim of this work was to evaluate the floristic and structural dynamics of a swamp

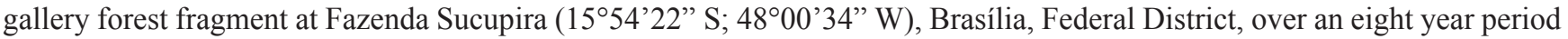
(2000 to 2008). Two measurements were carried out in 40 plots $(0.8 \mathrm{ha})$ of $20 \times 10 \mathrm{~m}$. All individuals with DAP $\geq 3.0 \mathrm{~cm}$ were recorded. The first measurement registered 3,048 individuals, distributed in 50 species, 41 genera (32 families). In the second measurement 2,728 individuals were found, belonging to 59 species, 48 genera (36 families). In 2008 there was a reduction of 320 individuals but an addition of 9 species, 7 genera and 4 families. The monitoring period showed high rates of mortality $\left(4.25 \%\right.$ year $\left.^{-1}\right)$ and recruitment $\left(3.67 \%\right.$ year $\left.^{-1}\right)$, changes in the importance of many species, without significant modification of the diversity index: $H^{\prime}=2.84$ nats ind. $.^{-1}, J^{\prime}=0.73$ in 2000 and $H^{\prime}=3.02$ nats ind. ${ }^{-1}, J^{\prime}=0.74$ in 2008 . This unique type of gallery forest seems to be dynamic in its floristic community, without detectable effects on structure and diversity. More studies focused on community dynamic, for longer periods are still needed for a better understanding of the swamp forest environment in Central Brazil, and to generate information for conservation action plans.
\end{abstract}

Key words - Cerrado, flood, riparian forest, swamp forest, tree community

RESUMO - (Dinâmica do componente arbóreo de uma mata de galeria inundável (Brasília, Distrito Federal) em um período de oito anos). As matas de galeria são importantes na manutenção dos recursos hídricos e da biodiversidade do Planalto Central, mas estão submetidas a fortes impactos antrópicos. Aquelas que ocorrem em solos mal drenados são pouquíssimo estudadas, com consequências negativas sobre sua conservação. Este trabalho objetivou avaliar a dinâmica florística e estrutural de um trecho de mata de galeria inundável na Fazenda Sucupira (1554'22" S; 48 00’34” W), Brasília, Distrito Federal, em um período de oito anos (2000 a 2008). Nas duas medições realizadas, em 40 parcelas $(0,8$ ha) de $20 \times 10 \mathrm{~m}$, foram amostrados todos os indivíduos arbóreos com DAP $\geq 3,0 \mathrm{~cm}$. A primeira medição registrou 3.048 indivíduos, distribuídos em 50 espécies e 41 gêneros (32 famílias). Na segunda medição foram encontrados 2.728 indivíduos, pertencentes a 59 espécies e 48 gêneros (36 famílias). Em 2008 verificou-se diminuição de 320 indivíduos, mas acréscimo de 9 espécies, 7 gêneros e 4 famílias. O período monitorado revelou altas taxas de mortalidade $\left(4,25 \% \mathrm{ano}^{-1}\right)$ e recrutamento $\left(3,67 \% \mathrm{ano}^{-1}\right)$, mudanças consideráveis na importância de muitas espécies, sem alterações significativas na diversidade: $H^{\prime}=2,84$ nats indivíduo ${ }^{-1}, J^{\prime}=0,73 \mathrm{em} 2000$; $H^{\prime}=3,02$ nats indivíduo ${ }^{-1}, J^{\prime}=0,74 \mathrm{em} \mathrm{2008}$. Esses ambientes diferenciados parecem ser muito dinâmicos em sua florística, sem que a estrutura comunitária e a diversidade sejam afetadas. Mais estudos de dinâmica, por períodos mais longos, ainda são necessários para que se possa compreender o ambiente florestal inundável do Brasil Central com mais segurança, gerando informações que subsidiem ações prementes de conservação.

Palavras-chave - Cerrado, comunidade arbórea, floresta paludosa, floresta ribeirinha, inundação

\section{Introdução}

As matas de galeria inundáveis são florestas sempreverdes do Brasil Central que acompanham cursos de água mal definidos, onde o lençol freático se mantém próximo ou sobre a superfície do terreno na maior parte dos trechos durante todo o ano, inclusive na estação

1. Universidade de Brasília, Departamento de Engenharia Florestal, Campus Universitário Darcy Ribeiro, Asa Norte, Caixa Postal 04357, 70919-970 Brasília, DF, Brasil.

2. Embrapa Recursos Genéticos e Biotecnologia, Cenargen/Herbário, Caixa Postal 02372, 70770-900 Brasília, DF, Brasil.

3. Autor para correspondência: bwalter@cenargen.embrapa.br seca (Walter \& Ribeiro 1997, Ribeiro \& Walter 2008). Floristicamente, são semelhantes às florestas latifoliadas higrófilas, paludosas ou também chamadas matas de brejo, encontradas essencialmente nos Estados de São Paulo (Torres et al. 1994, Costa et al. 1997, Ivanauskas et al. 1997, Toniato et al. 1998, Paschoal \& Cavassan 1999, Guarino \& Walter 2005, Teixeira \& Assis 2005, Teixeira et al. 2008) e Minas Gerais (Rocha et al. 2005, Silva et al. 2007).

Matas de galeria inundáveis apresentam peculiaridades florísticas que as diferenciam de outros tipos florestais, sejam esses matas de galeria nãoinundáveis dos planaltos brasileiros (exemplos em 
Oliveira Filho et al. 1990, Felfili 1995, 1997, Pinto \& Oliveira Filho 1999, Sampaio et al. 2000, Silva Júnior et al. 2001, Lopes \& Schiavini 2007, Oliveira \& Felfili 2008), como também matas periodicamente alagadas, mal drenadas, inundáveis, pantanosas, turfosas, higrófilas, hidrófilas ou aluviais de outras regiões (Lieberman et al. 1985, Ferreira \& Prance 1998, Meira Neto et al. 2003, Rocha et al. 2005, Arieira \& Cunha 2006, Martins et al. 2006, Silva et al. 2007, Giehl \& Jarenkow 2008, Guimarães et al. 2008). Nas matas de galeria inundáveis observa-se o predomínio de poucas espécies conspícuas, bem adaptadas àquele ambiente de estresse, que possuem ampla dominância local e que são enriquecidas por um conjunto maior de espécies raras ou que apresentam baixa importância fitossociológica (Walter 1995, Nogueira \& Schiavini 2003, Guarino \& Walter 2005, Dietzsch et al. 2006). Claramente, essas matas tendem a possuir diversidade menor que as matas de galeria não-inundáveis e a composição da comunidade é constituída predominantemente por indivíduos de espécies exclusivas desse ambiente (Walter \& Ribeiro 1997, Guarino \& Walter 2005). Em contrapartida, há sugestões de que o ambiente de estresse hídrico, ocasionado por má oxigenação do solo e diferenças nos padrões de sedimentação, pode favorecer processos de especiação, o que também contribuiria para aumentar a diversidade de espécies de uma região (Junk 1993).

A importância das matas ribeirinhas na manutenção da biodiversidade e qualidade dos recursos hídricos é reconhecida legalmente desde os anos 1960, com o Código Florestal (Lei no 4.771, de 15 de setembro de 1965) e dispositivos posteriores que os alteraram (Lei $\mathrm{n}^{\circ}$ 7.511, de 7 de julho de 1986). Porém, mesmo com a atual legislação ambiental brasileira, que dispõe sobre as Áreas de Preservação Permanente (APPs) (Lei 4.771/65, alterada pela MP 2166-67, e Resolução Conama no 303/2002) e que tem entre seus principais objetivos preservar a biodiversidade, a efetiva manutenção da diversidade florística e estrutural dessas matas não vem sendo garantida (Silva Júnior 2001). Com a contínua ameaça que esses ambientes sofrem, torna-se cada vez mais urgente a implementação de medidas mitigadoras que objetivem preservar a diversidade das matas de galeria, auxiliando na conservação e recuperação desses ambientes.

Matas de galeria inundáveis (sensu Ribeiro \& Walter 2008), ou mesmo trechos inundáveis de matas de galeria, carecem de estudos. Até o presente, as investigações fitossociológicas avançaram mais no triângulo mineiro (Nogueira \& Schiavini 2003) e no Distrito Federal e entorno, onde estão concentradas devido a alguns trabalhos diretos (Walter 1995, Beltrão 2003, Guarino \&
Walter 2005, Dietzsch et al. 2006), que são acrescidos de importantes informações encontradas em Ratter (1991), Silva Júnior (1998) e Sampaio et al. (2000). Porém, estudos de dinâmica dessas comunidades são inexistentes. Diante dessa situação, assim como vem sendo feito para outros tipos de florestas (ex. Lieberman \& Lieberman 1987, Swaine et al. 1987, Braga \& Rezende 2007, Lopes \& Schiavini 2007, Guimarães et al. 2008, Oliveira \& Felfili 2008), existe a necessidade de se conhecer a dinâmica desses fragmentos florestais ao longo do tempo e do espaço, permitindo um maior entendimento dos mecanismos que promovam e mantenham sua riqueza, e as possíveis variações estruturais decorrentes dos processos de reorganização frente às mudanças ambientais. Monitorar a dinâmica de florestas permite compreender a complexidade dos processos ecológicos, as interações entre as espécies, inseridas em condições ambientais heterogêneas moduladas no tempo e no espaço (Earn \& Rohani 1999).

Partindo da premissa de que a área se encontra em equilíbrio dinâmico (Swaine et al. 1987, Oliveira \& Felfili 2008), o presente estudo objetivou avaliar as mudanças florísticas, estruturais e a diversidade do componente arbóreo de um trecho de mata de galeria inundável no Distrito Federal (DF), em um período de oito anos (2000 a 2008).

\section{Material e métodos}

Área de estudo - Os estudos foram conduzidos na Fazenda Sucupira (FS), Brasília, DF, em um pequeno trecho da mata de galeria inundável $\left(15^{\circ} 54^{\prime} 22^{\prime}\right.$ 'S e $\left.48^{\circ} 00^{\prime} 34^{\prime \prime} \mathrm{W}\right)$ próximo ao Córrego Riacho Fundo. O clima predominante na região é do tipo Aw (tropical chuvoso), indicando invernos secos e verões chuvosos (Köppen 1948). A precipitação anual média é de aproximadamente $1.492 \mathrm{~mm}$ e a altitude local de cerca de $1.080 \mathrm{~m}$. Geologicamente, a Fazenda está inserida no grupo Paranoá (Walter \& Sampaio 1998). Os solos do trecho estudado pertencem à classe Gleissolo Melânico, de cor preta, que acumulam matéria orgânica não decomposta com cerca de 20 a $40 \mathrm{~cm}$ de espessura, sobre uma camada acinzentada (gleizada) com textura argilosa (Reatto et al. 2008).

A FS possui grande número de nascentes representadas principalmente pelos olhos d'água dos Córregos Açudinho e Açudinho I (Walter \& Sampaio 1998). O córrego mais caudaloso que passa na fazenda é o Riacho Fundo, um dos formadores do Lago Paranoá de Brasília. O trecho estudado localiza-se na margem direita do Riacho Fundo, após sua junção com o Córrego Açudinho, estando entremeado pelo pequeno córrego denominado Sem Nome. O trecho estudado é bem preservado, sem registro algum de antropismo direto. Embora o trecho não tenha sido perturbado, o córrego Riacho Fundo passou a receber grande carga de esgoto e águas 
pluviais nos últimos 10 anos, devido à ampliação urbana desordenada nas suas cabeceiras. Na faixa do dique na FS têm sido observadas alterações estruturais crescentes na mata, com o assoreamento do córrego, queda de árvores grandes devido às enchentes causadas por chuvas fortes, percebendo-se um adensamento de lianas e plantas ruderais contíguas ao córrego, e ampliação dos trechos com clareiras nas suas margens, cuja cobertura de gramíneas robustas e outras plantas invasoras vêm alterando a fisionomia original. Porém, esta situação de perturbação não alcança o trecho inundável estudado, já que as clareiras nas unidades amostrais, provavelmente, resultam de causas naturais, sendo um provável reflexo de ventos fortes em dias de chuvas intensas no verão.

Amostragem-Aamostragem consistiu na remedição, em 2008, das parcelas permanentes inventariadas em 2000 por Guarino \& Walter (2005), totalizando assim um intervalo de oito anos entre os dois levantamentos. A amostragem fitossociológica foi feita em uma grade de parcelas permanentes de forma retangular $(160 \times 50 \mathrm{~m})$, composta por 40 parcelas contíguas de $200 \mathrm{~m}^{2}(20 \times 10 \mathrm{~m})$, totalizando 0,8 ha amostrado.

Nos dois levantamentos, todos os indivíduos arbóreos com diâmetro medido a 1,30 m de altura do solo (DAP) maior ou igual a 3,0 cm foram amostrados, incluindo os indivíduos mortos que ainda estavam em pé. Para todos os indivíduos amostrados foram registrados dados de altura total, DAP e o nome da espécie, sendo que todos os indivíduos foram marcados com placas de alumínio. Na segunda medição plantas novas que entraram na amostragem receberam numeração crescente, em relação ao último indivíduo marcado no levantamento de 2000. Exemplares botânicos (vouchers) de todas as espécies amostradas foram coletados e estão depositados no herbário CEN. As famílias foram tratadas segundo APG II (2003).

Alguns nomes referidos por Guarino \& Walter (2005) foram modificados taxonomicamente no presente estudo, em função de revisão e atualizações na identificação dos vouchers. Três nomes foram eliminados, sendo um deles Psychotria carthagenensis Jacq., por identificação incorreta, que agora confirmou-se tratar de Psychotria mapourioides DC.; Cryptocaria sp. e Ocotea sp. agora foram tratadas sob uma única espécie: Nectandra cf. nitidula Nees \& Mart. Atualizações ocorreram de Gomidesia sp. para Myrcia magnoliifolia DC.; de Amaioua sp. para A. corymbosa Kunth; de Myrcia castrensis (O. Berg) Legrand para Marlierea lituatinervia (O. Berg) MacVaugh; de Ilex integrifolia Hort. ex Gardner para I. brasiliensis (Spreng.) Loes.; de Inga cf. ingoides (Rich.) Willd. para I. alba (Sw.) Willd.; e de Schefflera morototoni (Aubl.) Maguire, Steyerm. \& Frodin para S. calva (Cham.) Frodin \& Fiaschi.

Quanto ao recrutamento foram considerados os indivíduos que alcançaram, no período de amostragem, o critério mínimo de inclusão (DAP $\geq 3,0 \mathrm{~cm}$ ), e a mortalidade incluiu as árvores que caíram, tenham estas sido localizadas no chão da mata ou não. Para evitar possíveis sobreposições nas análises de mortalidade, os indivíduos mortos em pé não foram considerados, só sendo utilizados na análise estrutural. Como não há controle sobre quando teriam perecido os mortos em pé do ano 2000, e que a exclusão deste grupo em 2000 mais manutenção em 2008 poderia resultar em um viés de alta, optou-se por não incluir o grupo nesta análise.

Análises - Utilizando-se o programa Mata Nativa 2 (Cientec 2004), foram calculados para as espécies e para a comunidade os parâmetros fitossociológicos da estrutura horizontal, isto é, densidade (absoluta e relativa), dominância (absoluta e relativa), frequência (absoluta e relativa) e o Valor de Importância (Mueller-Dombois \& Ellemberg 1974), tanto para a medição feita em 2000 como na de 2008. A diversidade de espécies foi calculada pelo índice de Shannon $\left(H^{\prime}\right)$ e a equitabilidade pelo índice de Pielou ( $\left.J^{\prime}\right)$ (Magurran 1988).

Para avaliar a dinâmica dos indivíduos lenhosos, foram consideradas as variáveis mortalidade, recrutamento e incremento em diâmetro. Com base no número de indivíduos amostrados nas duas épocas monitoradas, foram calculadas as taxas de mortalidade e de recrutamento para a comunidade a partir do modelo algébrico de mortalidade indicado por Sheil et al. (1995):

$m=1-\left[1-\left(N_{0}-N_{1}\right) / N_{0}\right]^{1 / t}$

sendo

$N_{1}=N_{0}(1-m)^{t}$

onde:

$m=$ mortalidade por ano;

$N_{0}=$ número total de indivíduos na primeira amostragem;

$N_{1}=$ número total de indivíduos na segunda amostragem;

$t=$ intervalo de tempo.

Adequando-o para calcular as taxas de mortalidade e de recrutamento, tem-se que:

$T M=\left\{1-\left[\left(N_{\mathrm{i}}-m o\right) / N_{\mathrm{i}}^{1 / t}\right]\right\} 100$

$T R=\left\{1-\left[\left(N_{\mathrm{i}}-r e\right) / N_{\mathrm{i}}^{1 / t}\right]\right\} 100$

onde:

$T M=$ Taxa de mortalidade;

$T R=$ Taxa de recrutamento;

$N_{\mathrm{i}}=$ número total de indivíduos na primeira amostragem (exceto mortos em pé);

$m o=$ número de indivíduos mortos na segunda amostragem (exceto mortos em pé);

$r e=$ número de indivíduos recrutados na segunda amostragem;

$t=\quad$ intervalo de tempo em anos.

Para o cálculo destas taxas, em geral, tem sido mais utilizado o modelo logarítmico sugerido por Swaine \& Lieberman (1987), que assume um declínio exponencial (logarítmico) da mortalidade com o tempo. Porém, como Sheil et al. (1995) apontaram problemas com o uso deste modelo quando altas taxas de mortalidade são encontradas, embora ambos sejam relacionados e independentes do 
intervalo de tempo, optou-se pelo modelo algébrico. Como se trata da primeira avaliação daquele trecho inundável, cuja importância de mortos já era alta na primeira medição (Guarino \& Walter 2005), o uso de um modelo que estime a quantidade de mortalidade real seria mais adequado, como advogam Sheil et al. (1995). Não obstante, ambos (algébrico e logarítmico) são comparáveis e apresentam resultados próximos.

O incremento periódico anual (IPA), que expressa o crescimento anual de um indivíduo, foi obtido pela fórmula (Finger 1992):

$I P A=\frac{\sum_{i=1}^{n}(D A P 2 i-D A P 1 i)}{N}$

onde:

$I P A=$ incremento periódico anual $\left(\mathrm{em} \mathrm{cm} \mathrm{ano}^{-1}\right)$;

$D A P 2 i=$ diâmetro da iésima árvore viva na $2^{-a}$ medição;

$D A P 1 i=$ diâmetro da iésima árvore viva na 1ํㅡㄹ medição;

$N=$ número total de anos monitorado.

Incrementos negativos, basicamente ocasionados por perda de casca ou outro afinamento do fuste, e também perda das bases dos pecíolos persistentes nos caules em Cyathea, foram transformados para zero, de modo que esses casos foram considerados sem crescimento no período (Felfili 1995, Oliveira \& Felfili 2008). Indivíduos ausentes da amostra em 2000, naturalmente não puderam ter seu incremento calculado.

A distribuição dos indivíduos por classes de diâmetro e de altura, com intervalos regulares, foi analisada por meio de histogramas de frequência, seguindo o sistema de classes sugerido por Spiegel (1976). Para efeito de cálculo, os indivíduos cujos troncos possuíam bifurcações foram tratados por seu diâmetro quadrático $\left(d^{2}=\sqrt{d_{1}^{2}+d_{2}^{2}+d_{3}^{2}+\ldots+d_{\mathrm{n}}^{2}}\right)$, os mesmos considerados como um único fuste (indivíduo). Considerando que variáveis biológicas podem ser distribuídas em uma ou mais classes de frequência (Silvertown \& Doust 1993), o emprego de distribuições a determinada variável da comunidade proporciona informações interessantes no sentido de compreender seu comportamento (Scolforo \& Mello 2006). A distribuição diamétrica foi utilizada, pois sua caracterização permite inferir se a comunidade em questão pode ser considerada auto-perpetuante, ou seja, se o conjunto de suas populações apresenta ou não indivíduos potenciais para migração das menores classes para as classes maiores (Scolforo \& Mello 2006).

\section{Resultados e discussão}

Estrutura e florística - Em 2000, foram encontrados 3.048 indivíduos (incluindo 375 indivíduos mortos em pé), distribuídos em 50 espécies e 41 gêneros, pertencentes a 32 famílias, enquanto em 2008 foram amostrados 2.728 indivíduos (149 mortos em pé), distribuídos em 59 espécies e 48 gêneros, pertencentes a 36 famílias (tabela 1). Em 2008, houve redução de 320 indivíduos na comunidade e o acréscimo de nove espécies (Alchornea glandulosa, Eugenia aff. florida, Gomidesia pubescens, Inga nobilis, Lacistema hasslerianum, Licania cf. apetala, Miconia hirtella, Micropholis cf. gardneriana e Tibouchina cf. candolleana), seis gêneros (Alchornea, Eugenia, Gomidesia, Lacistema, Micropholis e Tibouchina) e quatro famílias (Chrysobalanaceae, Euphorbiaceae, Lacistemaceae e Sapotaceae).

Em 2000, as famílias com maior número de espécies foram Melastomataceae (6), Lauraceae (4), Rubiaceae (4) e Piperaceae (3) e, em 2008, Melastomataceae (8), Lauraceae (4), Rubiaceae (4), Myrtaceae (4) e Piperaceae (3). Destaque para Melastomataceae e Myrtaceae (tabela 1), que incorporaram duas novas espécies em cada amostra: Tibouchina cf. candolleana e Miconia hirtella, Eugenia aff. florida e Gomidesia pubescens, respectivamente. As famílias mencionadas sempre possuem grande destaque nos estudos de matas de galeria inundáveis (Nogueira \& Schiavini 2003, Guarino \& Walter 2005, Dietzsch et al. 2006), exceto Piperaceae. Provavelmente, isso se deve aos critérios de inclusão de espécies daqueles estudos, geralmente maiores que $5 \mathrm{~cm}$ de DAP, excluindo a maioria dos indivíduos de Piper.

Fabaceae (Leguminosae) possui muito baixa importância no trecho estudado, corroborando estudos de Ratter (1991), Walter (1995), Walter \& Ribeiro (1997), Paschoal \& Cavassan (1999), Guarino \& Walter (2005) e Ribeiro \& Walter (2008). Mesmo com o registro de mais uma espécie desta família na comunidade (Inga nobilis), a segunda na área, trata-se, também, somente do segundo indivíduo da família. Por motivos ainda a serem investigados, leguminosas não se estabelecem plenamente nas matas de galeria inundáveis dos planaltos do Brasil Central.

Em 2000, a espécie com maior Valor de Importância (VI), excluindo as plantas mortas em pé (grupo que possuía o maior VI), foi Ferdinandusa speciosa, seguida por Richeria grandis, Xylopia emarginata, Protium spruceanum e Protium heptaphyllum (tabela 1). Em 2008 (incluindo as plantas mortas em pé), as duas espécies mais importantes foram mantidas, mesmo tendo havido redução nos seus números de indivíduos (redução de 1,04\%, ou 62 indivíduos, para Ferdinandusa speciosa; e 1,25\%, correspondendo a 66 plantas, para Richeria grandis). Seguiram-nas Protium spruceanum, Miconia dodecandra e Miconia chartacea. Portanto, houve diminuição significativa no número de plantas mortas em pé (do primeiro VI em 2000 para o sexto em 2008) e de espécies como Xylopia emarginata, que passou da $4^{\mathrm{a}}$ para a $11^{\mathrm{a}}$ posição em VI. Esta espécie, 


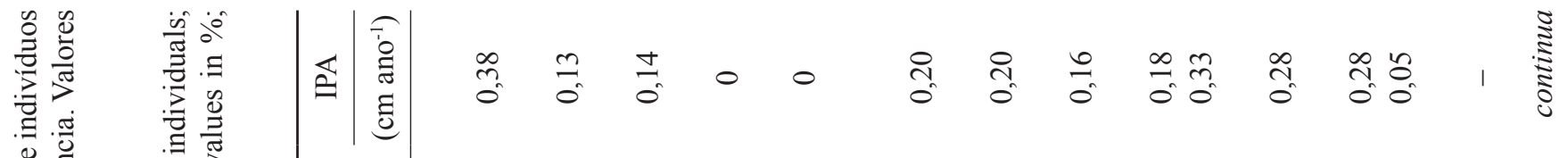

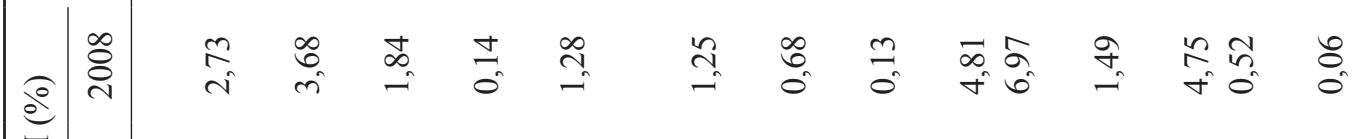

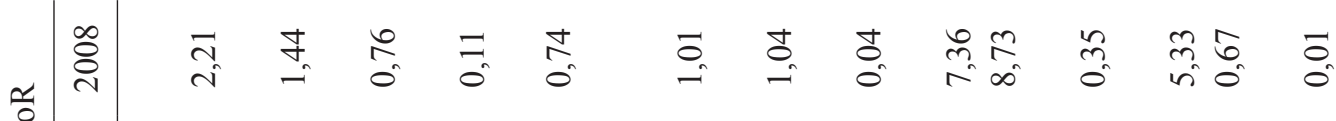

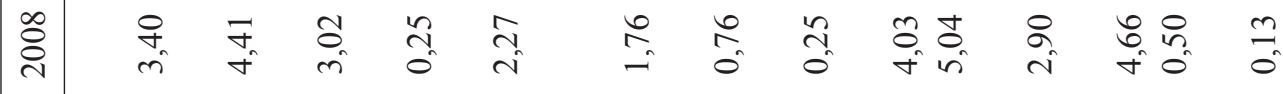
魚

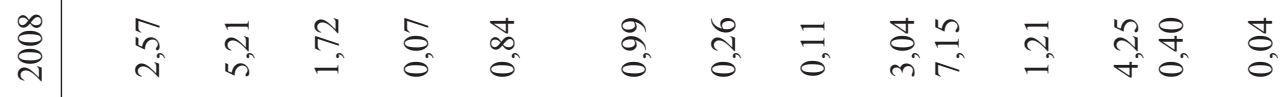
อี

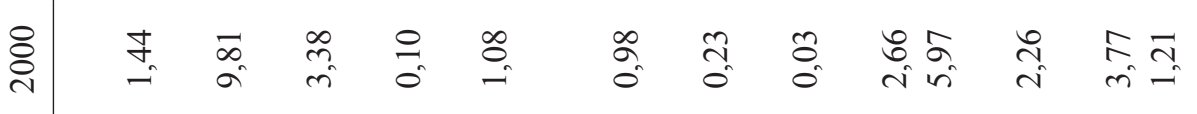

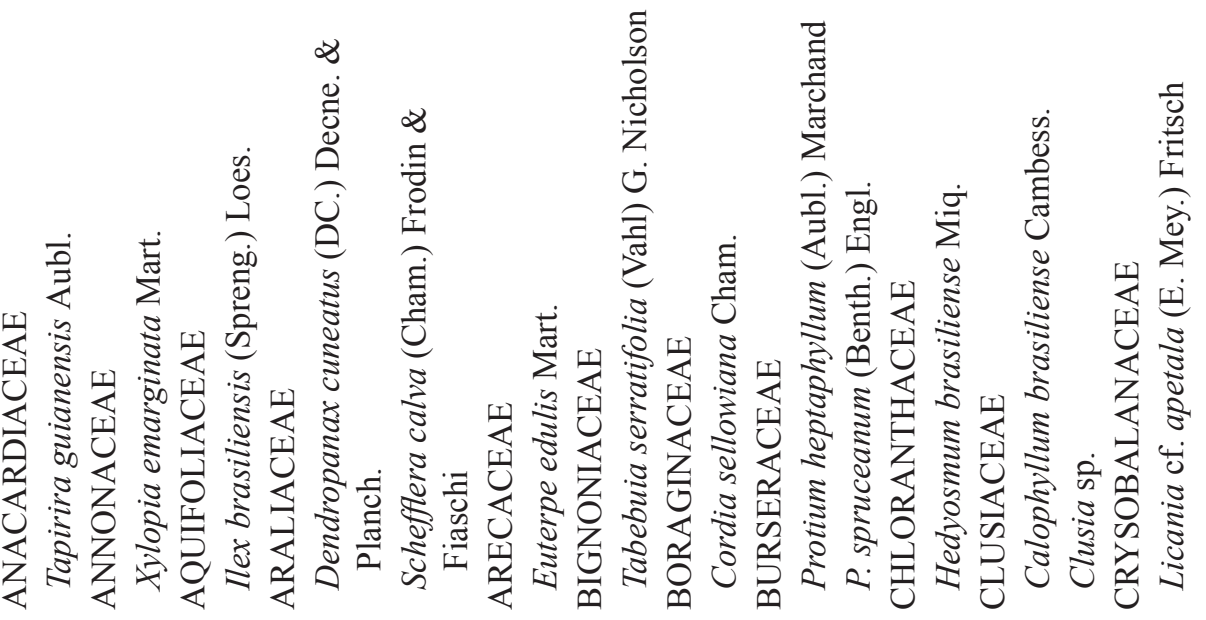




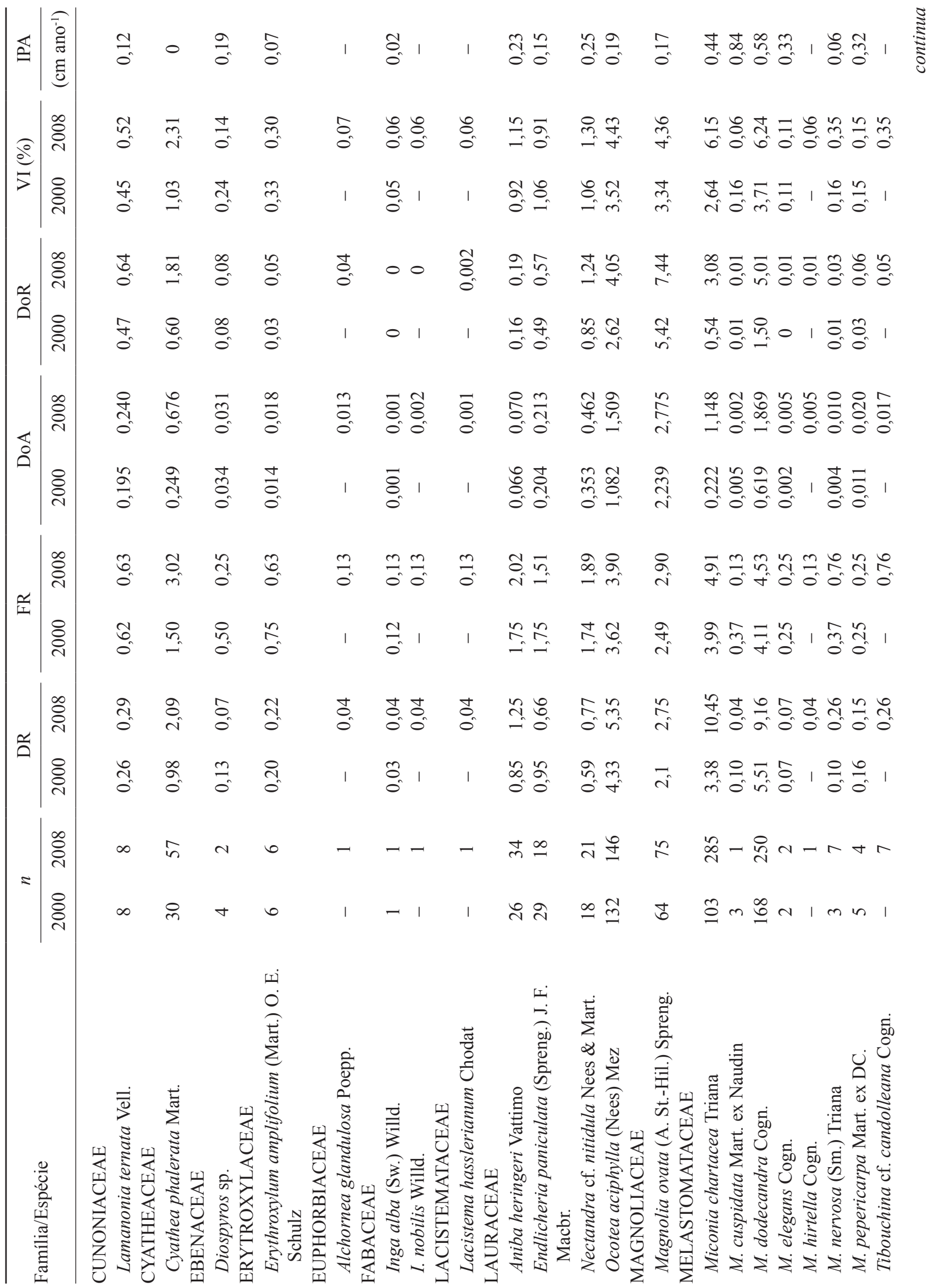




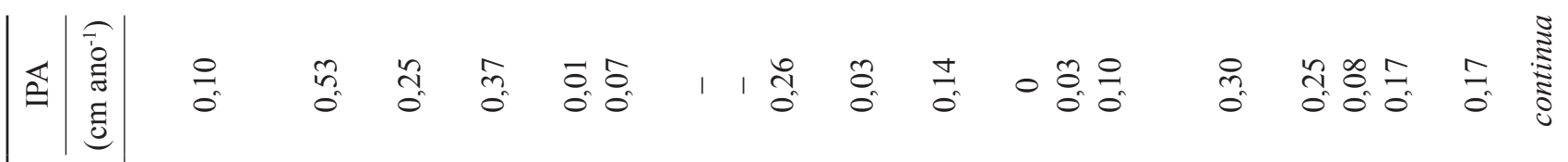

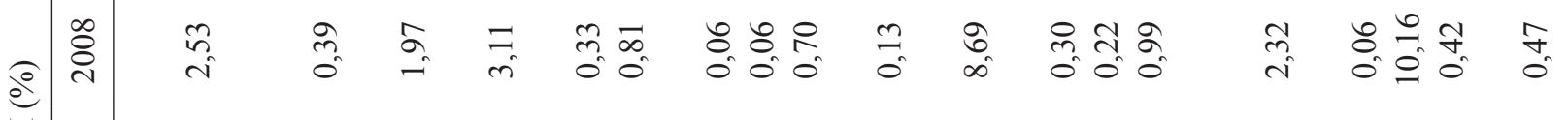

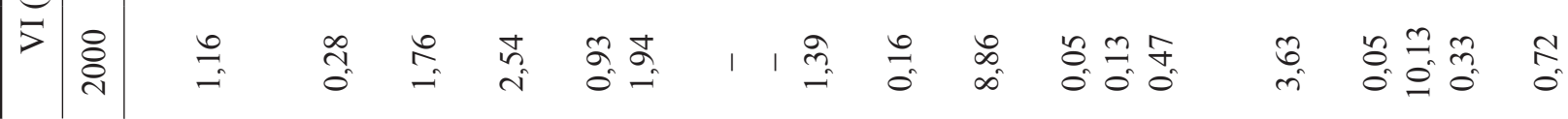

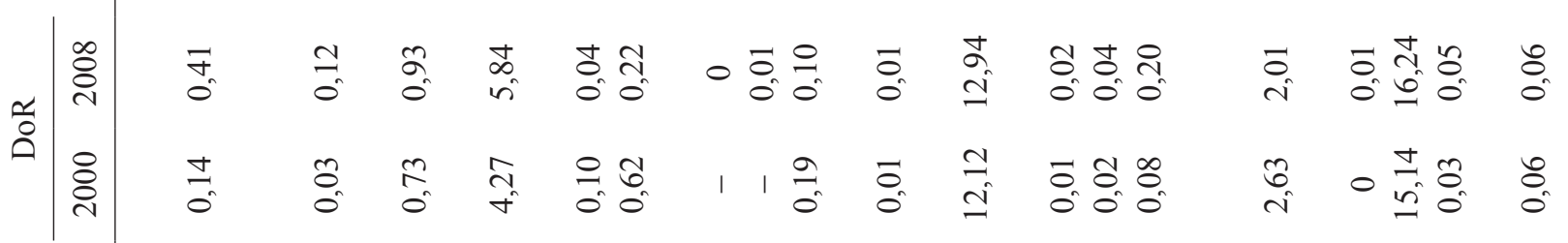

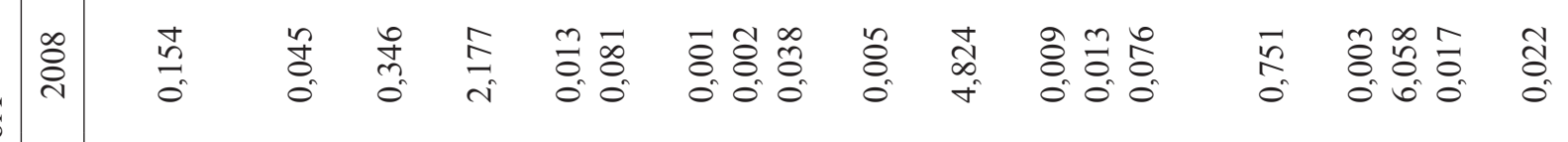
$\stackrel{\circ}{\circ}$

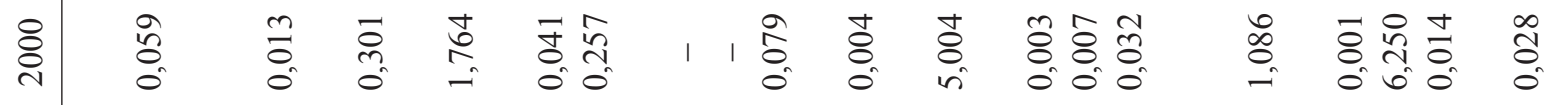

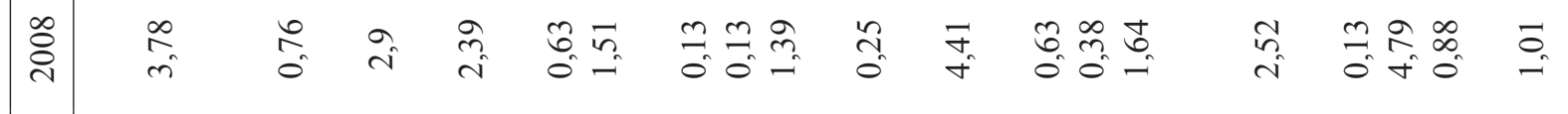
$\frac{\alpha}{1}$

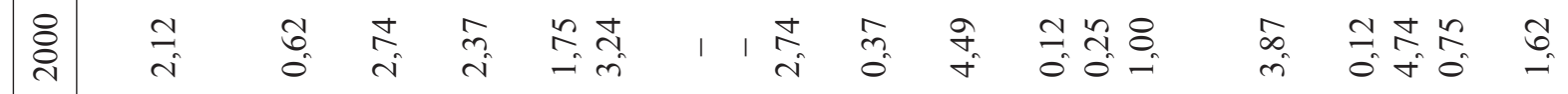

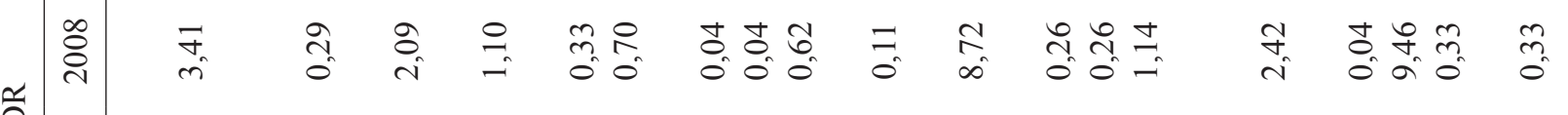
痌

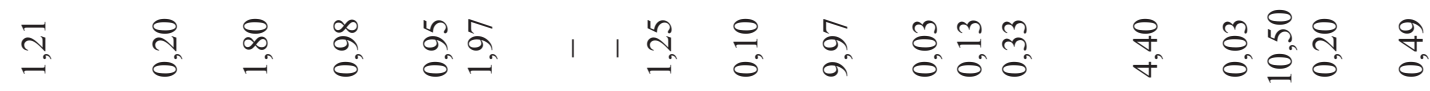

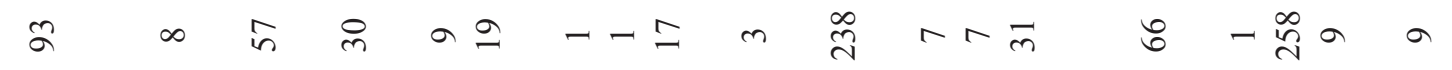

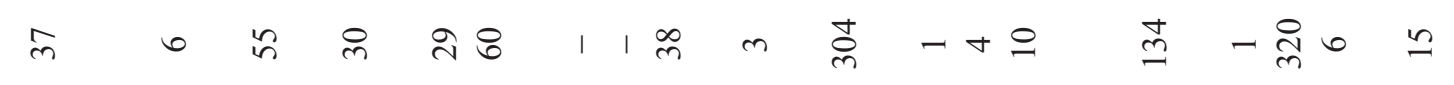

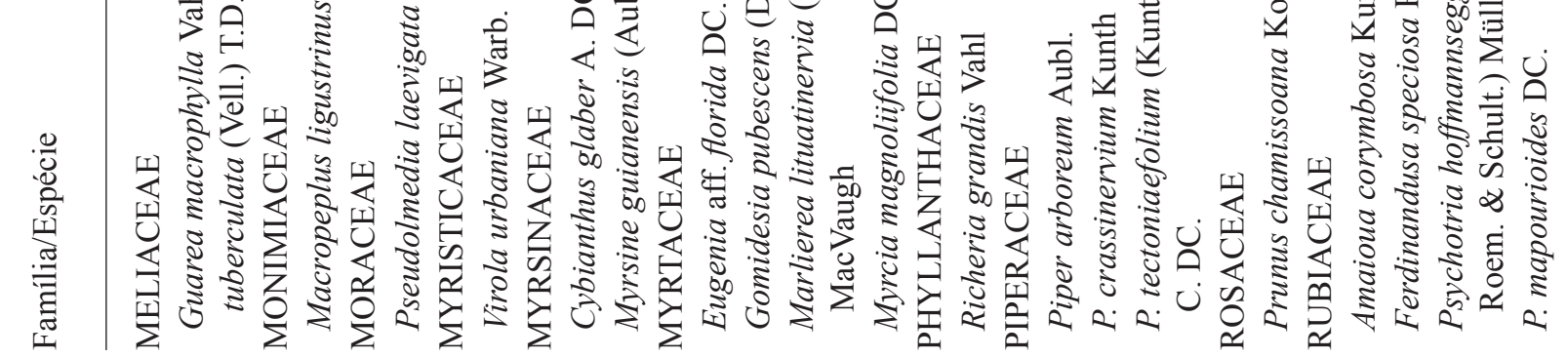




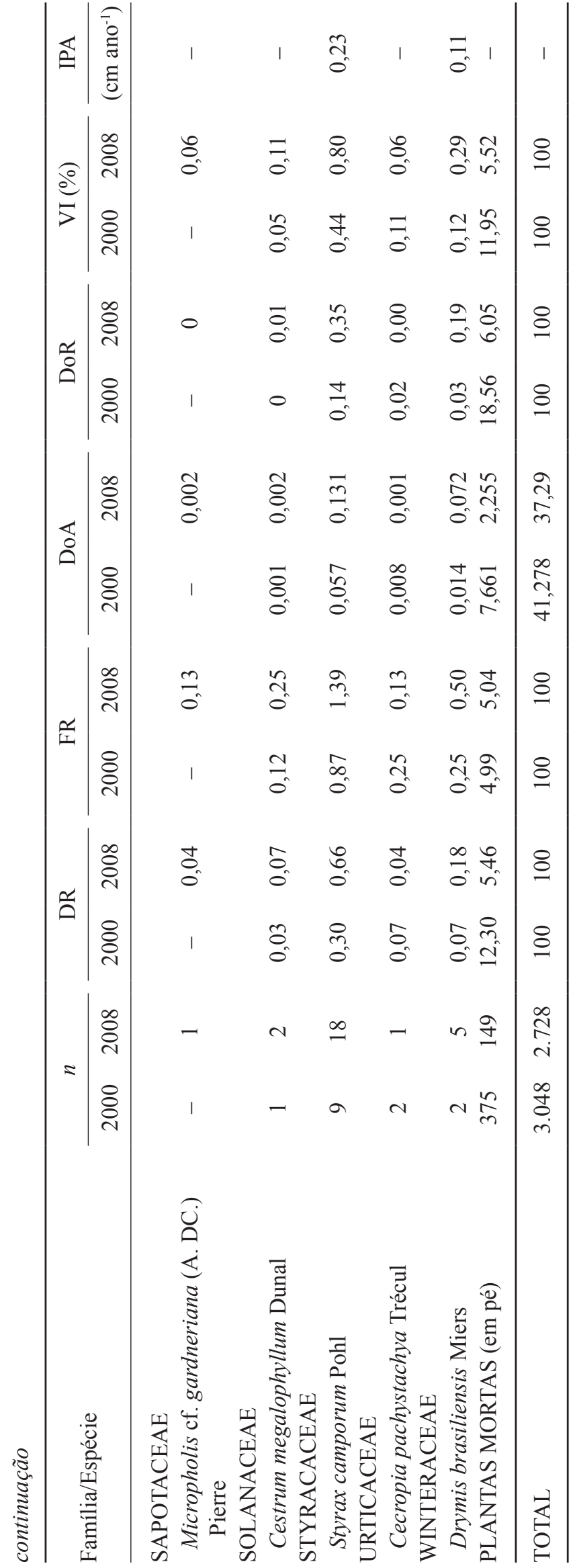

indicadora de solos saturados por água (Oliveira Filho et al. 1990, Walter \& Ribeiro 1997, Oliveira Filho \& Ratter 2002), contém o maior número de indivíduos que morreram no período (196 indivíduos), alguns dos quais passaram a categoria "plantas mortas em pé" e outros que efetivamente tombaram, saindo da amostragem o que se refletiu na diminuição da importância da espécie. Neste caso, foi observado em campo grandes indivíduos de Xylopia emarginata no chão da mata, contribuindo para a abertura de pequenas clareiras nas unidades amostrais.

Calophyllum brasiliense, 7ํㅡㄴ 2000 (com 115 indivíduos), passou para o $8^{\circ}$ VI em 2008, mesmo com a adição de um indivíduo (116). Prunus chamissoana também reduziu sua importância, passando da 9a posição para a 15a. O mesmo ocorreu com espécies como Hedyosmum brasiliense e Schefflera calva, dentre outras. Já plantas como Miconia dodecandra e M. chartacea ganharam importância, subindo do $8^{\circ}$ e $13^{\circ}$ lugar em VI para o $4^{\circ}$ e 5o, respectivamente. Isto foi consequência dos altos índices de recrutamento apresentados por essas espécies, os maiores da comunidade (105 e 191 indivíduos, respectivamente), e que parecem refletir a abertura de dossel ocasionada pela queda de árvores grandes, como as mencionadas Xylopia emarginata e Ferdinandusa speciosa. Ganhos significativos em densidade e importância também foram obtidos entre 2000 e 2008 por espécies arbóreas, como Tapirira guianensis (do 17음 para o 13 - VI) e Ocotea aciphylla (do $10^{\circ}$ para o $9^{\circ} \mathrm{VI}$ ); por arvoretas, como Guarea macrophylla subsp. tuberculata (37 indivíduos em 2000, 23ํ VI; alcançando 93 indivíduos em 2008, 14ํ VI) e Piper tectoniaefolium (10 indivíduos em 2000, 31ํVI; 31 indivíduos em 2008, 24ํㅡ); e, também, por plantas como a samambaia arborescente Cyathea phalerata $(30$ indivíduos em 2000, 26ํㅡI; 57 indivíduos em 2008, $16^{\circ}$ VI). A importância crescente das espécies de Miconia e Piper, além de Guarea e Cyathea, plantas de sub-bosque e sub-dossel (ou estrato inferior, conforme Ivanauskas et al. 1997) adaptadas a sombra, sugerem rápida ocupação das clareiras por espécies oportunistas, propiciada pela queda das grandes árvores no trecho amostrado.

Em contrapartida, comparando os dois momentos de monitoramento, observou-se diminuição na dominância total da área, o que pode ser explicado em parte pela redução na densidade total. Em $2000 \mathrm{DoA}=41,28 \mathrm{~m}^{2} \mathrm{ha}^{-1}$ e, em 2008, DoA $=37,29 \mathrm{~m}^{2}$ ha $^{-1}$ (tabela 1), indicando uma desocupação do terreno em quase $10 \%$. O fato de que árvores grossas foram eliminadas da amostragem no período não foi compensado na re-ocupação do terreno pelos demais indivíduos das espécies remanescentes emergentes, de dossel, ou mesmo pelas de sub-bosque 
ou pelos recrutas. Registre-se que troncos grossos caídos, ainda não decompostos, ocupam o solo impedindo o pleno estabelecimento de outras árvores, indicando que, futuramente, a re-ocupação do espaço por outros indivíduos poderá ocorrer.

As dez espécies mais importantes contribuíram com 55,03\% do VI total em 2000 e com 60,25\%, em 2008 (tabela 1). Isto significa incremento na importância fitossociológica das plantas mais abundantes, dominantes e frequentes sobre as demais espécies, ampliando o conjunto de plantas ocasionais e raras da área. Em outras palavras, as espécies comuns tornaram-se ainda mais comuns e o conjunto das raras foi ampliado. $\mathrm{O}$ aumento da riqueza constatado no período (de 50 para 59 espécies) também corrobora isto. Se esta é uma situação esperada, comum aos trechos inundáveis de matas de galeria, ainda é prematuro afirmar. Concordando com Swaine et al. (1987), a falta de estudos anteriores sobre a dinâmica deste tipo de ambiente e a duração ainda insuficiente do estudo não permite afirmações conclusivas no momento.

Diversidade - O índice de Shannon do trecho foi de 2,84 nats ind ${ }^{-1}$ em 2000, ampliando-se em 2008 para 3,02 nats ind $^{-1}$. Como esperado (Walter 1995, Sampaio et al. 2000, Guarino \& Walter 2005) trata-se de uma diversidade baixa, se comparada com matas de galeria não inundáveis do Brasil Central (tabela 2), cujos valores geralmente variam entre 3,60 até 4,45 nats ind ${ }^{-1}$ (ex. Felfili 1995, 1997, Silva Júnior 1998, Nóbrega et al. 2001). Porém, a diversidade é maior que aquela registrada para as matas de brejo ou paludosas paulistas (tabela 2), que,

Tabela 2. Diversidade florística de algumas florestas em ambientes mal drenados (paludosos) nas regiões sudeste e centro-oeste do Brasil. Primeira referência colocada para comparação. Fisionomias consideradas segundo o nome principal adotado no trabalho. $(\mathrm{CAP}=$ Circunferência à altura do peito $(1,3 \mathrm{~m})$; $\mathrm{DAP}=$ Diâmetro à altura do peito; $\mathrm{h}=$ altura do tronco; $-=$ dados não fornecidos no trabalho).

Table 2. Floristic diversity of some swamp forest environments in southeast and central-western Brazil. First reference placed for comparison. Physiognomies considered according to the main name adopted in the paper. (CAP = circumference at breast height $(1.3 \mathrm{~m}) ; \mathrm{DAP}=$ diameter at breast height; $\mathrm{h}=$ height of the trunk; $-=$ Data not provided at work).

\begin{tabular}{|c|c|c|c|c|c|c|c|}
\hline Fisionomia & Local & $\begin{array}{c}\text { Área } \\
\text { amostrada } \\
\left(\mathrm{m}^{2}\right)\end{array}$ & $\begin{array}{l}\text { Critério } \\
\text { de inclusão }\end{array}$ & $\begin{array}{c}H^{\prime} \\
\left(\text { nats ind }^{-1}\right)\end{array}$ & $J^{\prime}$ & $\begin{array}{l}\text { Riqueza } \\
\text { (no de } \\
\text { espécies) }\end{array}$ & Referência \\
\hline $\begin{array}{l}\text { Mata de galeria } \\
\text { (não-inundável) }\end{array}$ & Brasília (DF) & 18.400 & $\mathrm{CAP} \geq 20 \mathrm{~cm}$ & 4,45 & 0,85 & 186 & Nóbrega et al. (2001) \\
\hline $\begin{array}{l}\text { Mata de galeria } \\
\text { inundável }\end{array}$ & Brasília (DF) & 8.000 & $\mathrm{DAP} \geq 3 \mathrm{~cm}$ & 3,02 & 0,74 & 59 & Presente estudo \\
\hline $\begin{array}{l}\text { Mata de galeria } \\
\text { inundável }^{1}\end{array}$ & Brasília (DF) & 8.000 & $\mathrm{DAP} \geq 3 \mathrm{~cm}$ & 2,99 & 0,73 & 60 & $\begin{array}{l}\text { Guarino \& Walter } \\
\text { (2005) }\end{array}$ \\
\hline Floresta paludosa ${ }^{2}$ & Rio Claro (SP) & 1.500 & $\mathrm{~h}>1,3 \mathrm{~m}$ & $2,81^{3}$ & 0,64 & 77 & Teixeira et al. (2008) \\
\hline Floresta higrófila & Campinas (SP) & 2.000 & $\mathrm{CAP} \geq 10 \mathrm{~cm}$ & 2,80 & - & 55 & Toniato et al. (1998) \\
\hline Floresta de brejo & Itatinga (SP) & 10.000 & $\mathrm{CAP} \geq 15 \mathrm{~cm}$ & 2,75 & - & 39 & Ivanauskas et al. (1997) \\
\hline $\begin{array}{l}\text { Mata de galeria } \\
\text { inundável }\end{array}$ & Brasília (DF) & 2.800 & $\mathrm{DAP} \geq 5 \mathrm{~cm}$ & $2,57^{4}$ & 0,73 & 33 & Dietzsch et al. (2006) \\
\hline Mata de brejo & Brotas (SP) & 2.000 & $\mathrm{CAP} \geq 15 \mathrm{~cm}$ & 2,52 & - & 33 & Costa et al. (1997) \\
\hline Mata de brejo & Campinas (SP) & 8.700 & $\mathrm{DAP} \geq 5 \mathrm{~cm}$ & 2,45 & - & 33 & Torres et al. (1994) \\
\hline Mata de brejo & Agudos (SP) & 2.200 & $\mathrm{CAP} \geq 15 \mathrm{~cm}$ & $2,45^{5}$ & - & 38 & $\begin{array}{l}\text { Paschoal \& Cavassan } \\
\text { (1999) }\end{array}$ \\
\hline $\begin{array}{l}\text { Mata de galeria } \\
\text { inundável }\end{array}$ & Uberlândia (MG) & 6.200 & $\mathrm{CAP} \geq 15 \mathrm{~cm}$ & 2,27 & - & 33 & $\begin{array}{l}\text { Nogueira \& Schiavini } \\
(2003)\end{array}$ \\
\hline Floresta paludosa & Rio Claro (SP) & 4.500 & $\mathrm{CAP} \geq 15 \mathrm{~cm}$ & 2,10 & 0,54 & 49 & Teixeira \& Assis (2005) \\
\hline
\end{tabular}

${ }^{1}$ Considerados os valores da mata no Parque Nacional de Brasília. ${ }^{2}$ "Swamp forest" no original. ${ }^{3}$ Valores referentes apenas ao mais diverso conjunto de três grupos de parcelas com $1.500 \mathrm{~m}^{2}$ cada. O menos diverso teve $H^{\prime}=2,13$ nats ind $^{-1}\left(J^{\prime}=0,58\right) .{ }^{4}$ Valores referentes apenas ao trecho de mata de galeria inundável. ${ }^{5}$ No corpo do trabalho é indicado o valor 2,60.

${ }^{1}$ Considering the values for the forest in the National Park of Brasilia. " "Swamp forest" in the original. ${ }^{3}$ Referred only to values of the most diverse set of three groups of plots with $1,500 \mathrm{~m}^{2}$. The least diverse set was $H^{\prime}=2.13$ nats ind ${ }^{-1}\left(J^{\prime}=0.58\right) .{ }^{4}$ Referred only to values of the swamp gallery forest portion. ${ }^{5}$ In the text it is shown the value 2.60 . 
conforme Walter (1995), Nogueira \& Schiavini (2003) e Guarino \& Walter (2005), possuem grande afinidade florística e estrutural com as matas de galeria inundáveis. Comparado às poucas matas estudadas, com condições ambientais similares, fique registrado que o trecho do Riacho Fundo apresentou a diversidade mais elevada, devendo ser levadas em consideração as diferenças de métodos entre os trabalhos (tabela 2).

$\mathrm{O}$ índice de Pielou não apresentou variação significativa em relação às duas medições feitas: $J^{\prime}=0,73$ em 2000 e 0,74 em 2008 (tabela 2). Isso revela boa distribuição dos indivíduos entre as espécies no interior da mata, que apresentou uniformidade alta. Essa característica também era esperada, pois estudos anteriores (Walter 1995, Silva Júnior 1998, Nogueira \& Schiavini 2003, Guarino \& Walter 2005, Dietzsch et al. 2006) ressaltaram que as matas de galeria inundáveis apresentam menor riqueza em espécies, porém com uma distribuição mais uniforme dessa riqueza.

Uma síntese das análises da diversidade é que, mesmo frente aos eventos de abertura de clareiras e mudanças significativas nas posições das espécies mais importantes da comunidade, com aumento da riqueza em um período relativamente curto (oito anos), a diversidade do trecho estudado não se alterou de forma significativa.

Recrutamento e mortalidade - No período monitorado foram recrutados 699 indivíduos, resultando em uma taxa de recrutamento de 3,67\% ao ano. Sete dos indivíduos que entraram no período foram registrados em 2008 já como "plantas mortas em pé". Essa taxa de recrutamento pode ser considerada alta, quando comparada com outros trabalhos (tabela 3), sendo que a taxa registrada por Pinto (2002) foi a que apresentou valor mais próximo ao do presente estudo. Para efeito de investigação, mesmo considerando um critério de inclusão mínimo de $5 \mathrm{~cm}$ de DAP, a taxa de recrutamento seria ainda maior (tabela 3), resultante do aumento na proporção de recrutas em relação ao número inicial de indivíduos. Sendo assim, pela comparação com outros trabalhos e considerando o histórico de perturbação do trecho, é possível sugerir que as matas inundáveis parecem apresentar taxas elevadas de recrutamento, aparentemente maiores que as matas de galeria não inundáveis, embora sejam necessários mais estudos para corroborar esta sugestão. Não obstante, devem ser salientadas as limitantes diferenças dos critérios de inclusão entre os trabalhos.

A taxa de mortalidade do trecho estudado também foi alta, de 4,25\% ao ano (tabela 3 ), com um total de 785 indivíduos eliminados da amostra. Se considerado o
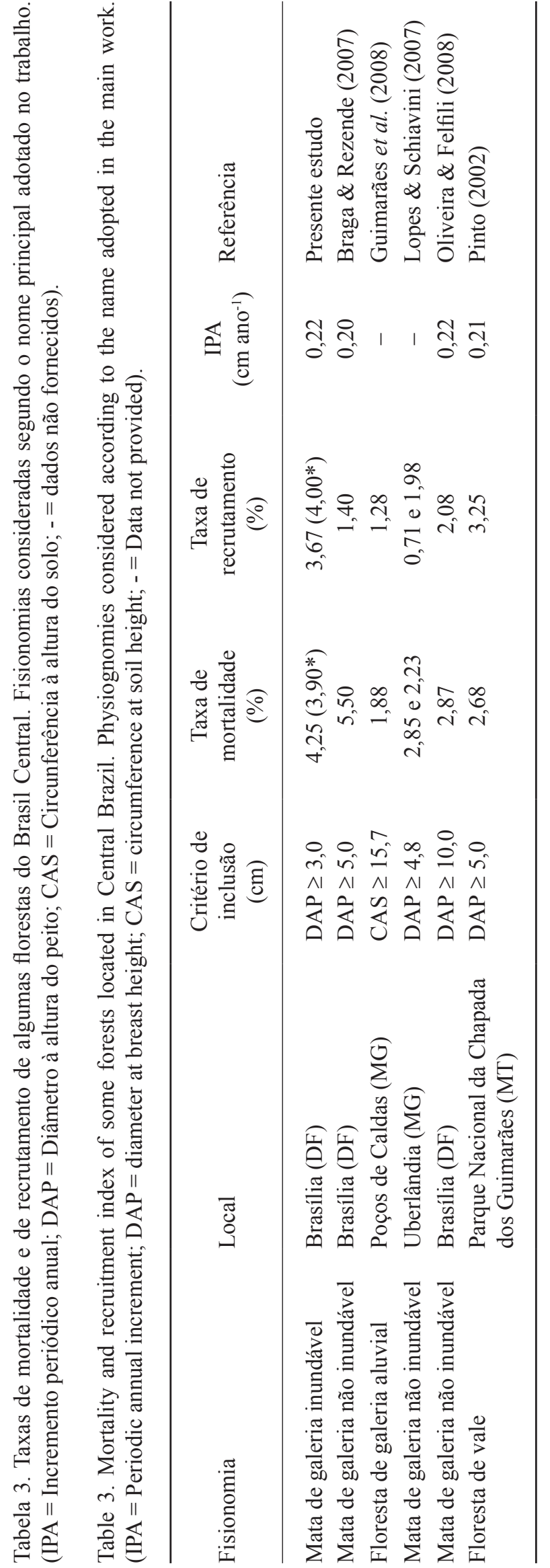

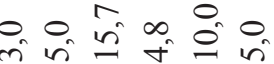

$\wedge \wedge \mathrm{I} \wedge \wedge \mathrm{I} \wedge \mathrm{I}$

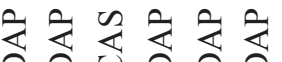
过
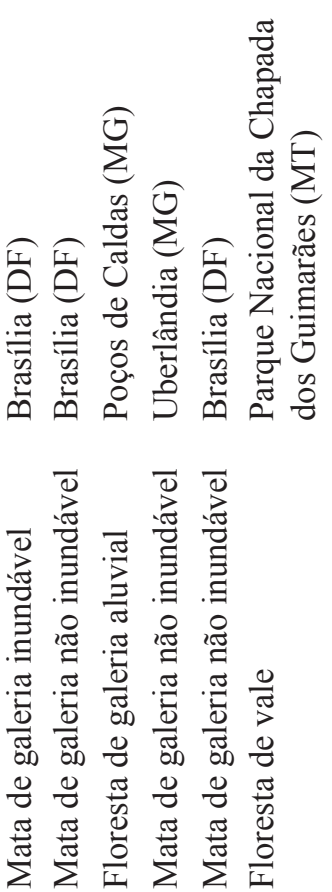
critério de inclusão de $5 \mathrm{~cm}$ de DAP, a taxa de mortalidade seria um pouco mais baixa, $3,90 \%$ ao ano (tabela 3 ). Ainda assim, o valor encontrado só seria inferior ao registrado por Braga \& Rezende (2007), com a elevada taxa de 5,5\% ao ano. Estes autores atribuíram o alto valor ao intervalo de tempo entre as duas medições (11 anos), por eles considerado longo. Comentaram que as informações sobre a dinâmica de uma formação vegetal podem ser influenciadas pelo intervalo entre medições, $o$ que pode levar a conclusões incorretas sobre os processos que estariam ocorrendo na floresta. Se for correta esta sugestão, seria importante buscar intervalos mais curtos entre as medições.

Em florestas tropicais não perturbadas há um equilíbrio entre as taxas de recrutamento e de mortalidade (Swaine et al. 1987, Silvertown \& Doust 1993, Braga \& Rezende 2007). O trecho de mata de galeria inundável do Córrego Riacho Fundo apresentou taxa de mortalidade maior que a de recrutamento, com diminuição na densidade de indivíduos (146 indivíduos), redução na área basal da comunidade (diminuição em 3,99 $\mathrm{m}^{2} \mathrm{ha}^{-1}$ ), embora isto não tenha influenciado os índices de diversidade. $\mathrm{O}$ desequilíbrio entre recrutamento e mortalidade (não observado para indivíduos com DAP $\geq 5 \mathrm{~cm}$ - tabela 3) pode ser atribuído a mortalidade ocorrer primeiro, sendo sucedida pelo recrutamento (Felfili 1995, Pulz et al. 1999). Jorgen \& Henrik (1994) argumentaram que a mortalidade de indivíduos de grande porte pode propiciar um aumento nas taxas de crescimento de determinadas espécies, o que pode ser explicado pela ampliação na disponibilidade de recursos como luz, nutrientes, água e energia aos demais indivíduos da comunidade.

No presente estudo, os altos valores de mortalidade e recrutamento poderiam ter sido influenciados pelo diâmetro mínimo de inclusão adotado (3,0 cm de DAP), já que a maioria dos trabalhos citados adotou diâmetros superiores a $5,0 \mathrm{~cm}$. Porém, a investigação com este critério mínimo não modificou o cenário. A queda de grandes árvores do trecho, com a consequente abertura de clareiras permitindo que indivíduos de outras espécies se estabeleçam no local, também foi preponderante para esses resultados. Sendo assim, nossos dados sugerem que trechos inundáveis de matas de galeria parecem possuir uma dinâmica acelerada, com altos índices de mortalidade e de recrutamento; o que se opõe ao que vem sendo evidenciado em florestas tropicais nas últimas três décadas (Swaine et al. 1987) e que foi recentemente observado (Guimarães et al. 2008) em uma floresta de galeria aluvial no sul de Minas Gerais. Somente com acompanhamentos futuros é que será possível fazer inferências mais seguras sobre o tema.
Incremento periódico anual - No período de oito anos o Incremento Periódico Anual (IPA) da comunidade arbórea estudada foi de $0,22 \mathrm{~cm} \mathrm{ano}^{-1}$. Comparando este valor com os que estão registrados em outros trabalhos (tabela 3), que variam de 0,20 a $0,25 \mathrm{~cm} \mathrm{ano}^{-1}$, percebese que não há variação entre os IPAs, indicando que a condição de alagamento não parece influenciar o incremento da comunidade.

Vinte espécies apresentaram IPA maior que o calculado para a comunidade e trinta apresentaram IPA menor (tabela 1). O maior valor foi de Miconia cuspidata $\left(0,84 \mathrm{~cm} \mathrm{ano}^{-1}\right)$ e, das que apresentaram crescimento, o menor foi de Cybianthus glaber $\left(0,01 \mathrm{~cm}^{\mathrm{c} n \mathrm{~N}^{-1}}\right)$. Duas espécies amostradas em 2000 (Cestrum megalophyllum e Cecropia pachystachya) não proporcionaram IPA, pois os indivíduos inventariados naquela medição morreram no período. Para ambas, os indivíduos amostrados em 2008 entraram como recrutas. Espécies como Miconia dodecandra e $M$. chartacea, que apresentaram grande aumento no VI, também apresentaram IPAs altos, quando comparadas com outras espécies: 0,58 e 0,44, respectivamente (tabela 1 ).

Os indivíduos com DAP $\leq 10 \mathrm{~cm}$ contribuíram com $38 \%$ do IPA total e $69 \%$ do IPA foi representado por indivíduos com DAP $\leq 15 \mathrm{~cm}$, sugerindo que o incremento de indivíduos mais jovens é maior que o de indivíduos mais maduros. Quando se comparam os valores do IPA de Tapirira guianensis, uma espécie pioneira, e Protium heptaphyllum, espécie clímax exigente por luz (Pinto 2002), verifica-se que a primeira apresenta maior incremento $(0,38$ e $0,18 \mathrm{~cm}$ $\mathrm{ano}^{-1}$, respectivamente). Em floresta de vale (MT), Pinto (2002) também constatou que o incremento das espécies pioneiras foi maior do que aquele das espécies clímax exigentes de luz $(0,32$ e $0,19 \mathrm{~cm}$ $\mathrm{ano}^{-1}$, respectivamente). A diferença no crescimento pode estar relacionada com seus grupos ecológicos (Swaine \& Whitmore 1988), corroborando a idéia de alguns autores que acreditam que as espécies pioneiras apresentam crescimento mais acelerado e período de vida mais curto.

Distribuição em classes de diâmetro e de altura - A distribuição diamétrica da comunidade em estudo apresentou a clássica forma de J-invertido, tanto para a primeira medição em 2000 quanto em 2008 (figura 1). $\mathrm{O}$ trecho amostrado apresenta principalmente indivíduos jovens, pois quase $50 \%$ do total de indivíduos amostrados estão inseridos na primeira classe diamétrica $(3,0$ a $6,5 \mathrm{~cm}$ ). O diâmetro máximo encontrado foi de 47,7 cm, pertencente a um indivíduo de Magnolia ovata. 


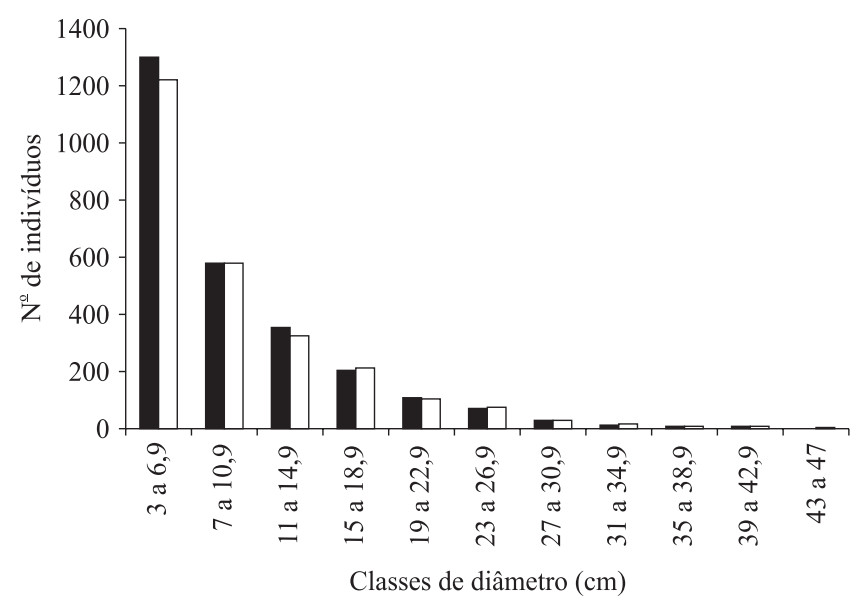

Figura 1. Distribuição diamétrica da comunidade arbórea do trecho de mata de galeria inundável do Córrego Riacho Fundo nos anos 2000 e 2008. ( $(\boldsymbol{\square}=2000 ; \square=2008)$.

Figure 1. Diametric distribution of a tree community in a portion of Riacho Fundo swamp gallery forest in 2000 and 2008. ( $\mathbf{\square}=2000 ; \square=2008)$.

Adistribuição de alturas da comunidade caracterizouse pelo acúmulo de indivíduos nas classes intermediárias (figura 2), uma possível consequência de recrutamento reduzido. Porém, Felfili (1995) indicou que padrões como estes ocorrem com espécies que necessitam de grande quantidade de luz (clareiras) para se estabelecerem e se desenvolverem. No trecho estudado, os maiores indivíduos alcançaram $27 \mathrm{~m}$ de altura, para plantas

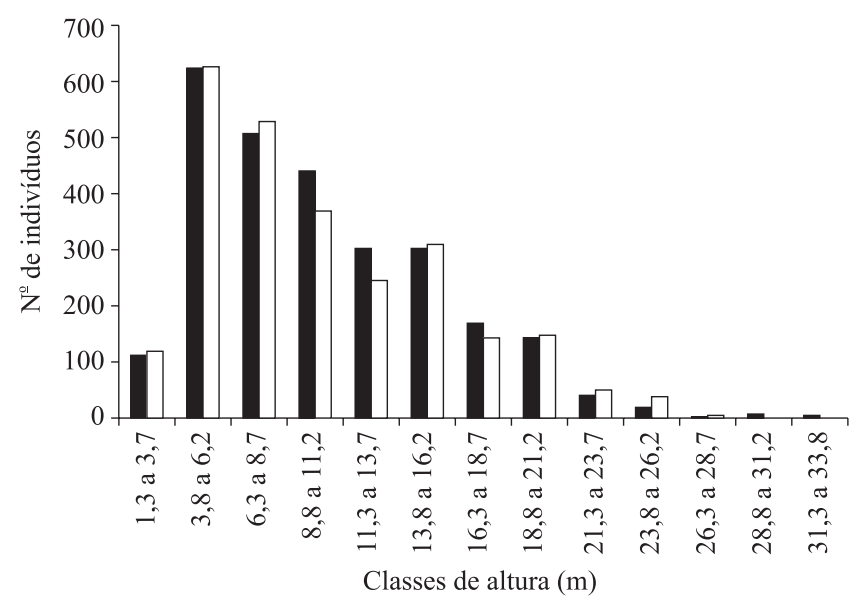

Figura 2. Distribuição de alturas da comunidade arbórea do trecho de mata de galeria inundável do Córrego Riacho Fundo nos anos de 2000 e 2008. ( $\square=2000 ; \square=2008)$.

Figure 2. Height distribution of a tree community in a portion of Riacho Fundo swamp gallery forest in 2000 and 2008. ( $=2000 ; \square=2008)$. emergentes de Magnolia ovata, Ocotea aciphylla, Protium heptaphyllum e Virola urbaniana.

As altas taxas de mortalidade e recrutamento no trecho de mata inundável do Riacho Fundo e as consideráveis modificações nos valores de importância das espécies em um período de tempo curto apontam para uma dinâmica comunitária acelerada, com numerosas substituições de indivíduos e de espécies, sem que a diversidade seja afetada significativamente. Parece surgir, assim, um padrão próprio para este tipo de mata, ainda não verificado para outras fitofisionomias do bioma Cerrado. Como os estudos neste ambiente mal drenado são escassos, ainda é necessário estimular novas pesquisas, principalmente estudos de dinâmica e de regeneração natural dessas matas.

Agradecimentos - Agradecemos aos colegas João Benedito Pereira, Bernardo Teixeira e Rafael Albuquerque pelo auxílio nos trabalhos de campo, Eliana Fontes pelo auxílio no abstract, Carolyn Proença pela ajuda na identificação das Myrtaceae e aos revisores anônimos pelas sugestões, que muito contribuíram para o artigo.

\section{Referências bibliográficas}

APG II. 2003. An update of the Angiosperm Phylogeny Group classification for the orders and families of flowering plants: APG II. Botanical Journal of the Linnean Society 141:399-436.

ARIEIRA, J. \& CUNHA, C.N. 2006. Fitossociologia de uma floresta inundável monodominante de Vochysia divergens Pohl (Vochysiaceae), no Pantanal Norte, MT, Brasil. Acta Botanica Brasilica 20: 569-580.

BELTRÃO, L. 2003. Avaliação do efeito do entorno na integridade ecológica de uma mata de galeria inundável no Distrito Federal. Dissertação de mestrado, Universidade de Brasília, Brasília.

BRAGA, F.M.S. \& REZENDE, A.V. 2007. Dinâmica da vegetação arbórea da mata de galeria do Catetinho, Brasília-DF. Cerne 13:138-148.

CIENTEC. 2004. Software Mata Nativa - Sistema para análise fitossociológica e elaboração de planos de manejo de florestas nativas. Cientec, Viçosa.

COSTA, F.R.C., SCHITTLER, F.H.M., CESAR, O. \& MONTEIRO, R. 1997. Aspectos florísticos e fitossociológicos de um remanescente de mata de brejo no município de Brotas, SP. Arquivos de Biologia e Tecnologia 40:263-270.

DIETZSCH, L., REZENDE, A.V., PINTO, J.R.R. \& PEREIRA, B.A.S. 2006. Caracterização da flora arbórea de dois fragmentos de mata de galeria do Parque Canjerana, DF. Cerne 12:201-210. 
EARN, D.J.D. \& ROHANI, P. 1999. Complex dynamics in ecology. Trends in Ecology and Evolution 2:43-44.

FELFILI, J.M. 1995. Diversity, structure and dynamics of a gallery forest in central Brazil. Vegetatio 117:1-15.

FELFILI, J.M. 1997. Dynamics of the natural regeneration in the Gama gallery forest in central Brazil. Forest Ecology and Management 91:235-245.

FERREIRA, L.V. \& PRANCE, G.T. 1998. Structure and species richness of low-diversity floodplain forest on the rio Tapajós, eastern Amazonia, Brazil. Biodiversity and Conservation 7:585-596.

FINGER, C.A.G. 1992. Fundamentos de biometria florestal. Universidade de Santa Maria, Santa Maria.

GIEHL, E.L.H. \& JARENKOW, J.A. 2008. Gradiente estrutural no componente arbóreo e relação com inundações em uma floresta ribeirinha, rio Uruguai, sul do Brasil. Acta Botanica Brasilica 22:741-753.

GUARINO, E.S.G. \& WALTER, B.M.T.2005. Fitossociologia de dois trechos inundáveis de matas de galeria no Distrito Federal, Brasil. Acta Botanica Brasilica 19: 431-442.

GUIMARÃES, J.C.C., VAN DEN BERG, E., CASTRO, G.C., MACHADO, E.L.M. \& OLIVEIRA FILHO, A.T. 2008. Dinâmica do componente arbustivo-arbóreo de uma floresta de galeria aluvial no planalto de Poços de Caldas, MG, Brasil. Revista Brasileira de Botânica 31:621-632.

IVANAUSKAS, N.M., RODRIGUES, R.R. \& NAVE, A.G. 1997. Aspectos ecológicos de um trecho de floresta de brejo em Itatinga, SP: florística, fitossociologia e seletividade de espécies. Revista Brasileira de Botânica 20:139-153.

JORGEN, K. \& HENRIK, B. 1994. Growth and mortality of tree in Amazonian tropical rain forest in Ecuador. Journal of Vegetation Science 4:7-86.

JUNK, W.J. 1993. Wetlands of tropical South America. In Wetlands of the world I: inventory, ecology and management (D. Whigham, S. Hejný \& D. Dykyjová, eds.). W. Junk Publishing, Boston, p.679-739.

KÖPPEN, W.P. 1948. Climatologia: con un studio de los climas de la tierra. Fondo de Cultura Económica, México.

LIEBERMAN, D. \& LIEBERMAN, M. 1987. Forest tree growth and dynamics at La Selva, Costa Rica (19691982). Journal of Tropical Ecology 3:347-358.

LIEBERMAN, M., LIEBERMAN, D., HARTSHORN, G.S. \& PERALTA, R. 1985. Small-scale altitudinal variation in lowland wet tropical forest vegetation. Journal of Ecology. 73:505-516.

LOPES, S.F. \& SCHIAVINI, I. 2007. Dinâmica da comunidade arbórea de mata de galeria da Estação Ecológica do Panga, Minas Gerais, Brasil. Acta Botanica Brasilica 21:249-261.

MAGURRAN, A.E. 1988. Ecological diversity and its measurement. Croom Helm, London, Sydney.
MARTINS, A.K.E., SCHAEFER, C.E.G.R., SILVA, E., SOARES, V.P., CORRÊA, G.R. \& MENDONÇA, B.A.F. 2006. Relações solo-geoambiente em áreas de ocorrência de Ipucas na planície do médio Araguaia Estado do Tocantins. Revista Árvore 30:297-310.

MEIRA NETO, J.A.A., RÊGO, M.M., COELHO, D.J.S. \& RIBEIRO, F.G. 2003. Origem, sucessão, e estrutura de uma floresta de galeria periodicamente alagada em Viçosa-MG. Revista Árvore 27:561-574.

MUELLER-DOMBOIS, D. \& ELLEMBERG, H. (eds.). 1974. Aims and methods of vegetation ecology. John Wiley, New York.

NÓBREGA, M.G.G., RAMOS, A.E. \& SILVA JÚNIOR, M.C. 2001. Composição florística e estrutura na mata de galeria do Cabeça-de-Veado no Jardim Botânico de Brasília, DF. Boletim do Herbário Ezechias Paulo Heringer 8:44-65.

NOGUEIRA, M.F. \& SCHIAVINI, I. 2003. Composição florística e estrutural da comunidade arbórea de uma mata de galeria inundável em Uberlândia, MG, Brasil. Bioscience Journal 19:89-98.

OLIVEIRA, A.P. \& FELFILI, J.M. 2008. Dinâmica da comunidade arbórea de uma mata de galeria do Brasil Central em um período de 19 anos (1985-2004). Revista Brasileira de Botânica 31:597-610.

OLIVEIRA FILHO, A.T. \& RATTER, J.A. 2002. Vegetation physiognomies and woody flora of the Cerrado biome. In The Cerrados of Brazil: ecology and natural history of a neotropical savanna. (P.S. Oliveira, \& R.J. Marquis, eds.). Columbia University Press, New York, p.91-120.

OLIVEIRA FILHO, A.T., RATTER, J.A. \& SHEPHERD, G.J. 1990. Floristic composition and community structure of a Brazilian gallery forest. Flora 184: 103-117.

PASCHOAL, M.E.S. \& CAVASSAN, O. 1999. A flora arbórea da mata de brejo do Ribeirão Pelintra, Agudos - SP. Naturalia 4:171-191.

PINTO, J.R.R. 2002. Dinâmica da comunidade arbóreoarbustiva em uma floresta de vale no Parque Nacional da Chapada dos Guimarães, Mato Grosso. Tese de doutorado, Universidade de Brasília, Brasília.

PINTO, J.R.R. \& OLIVEIRA FILHO, A.T. 1999. Perfil florístico e estrutura da comunidade arbórea de uma floresta de vale no Parque Nacional da Chapada dos Guimarães, Mato Grosso, Brasil. Revista Brasileira de Botânica 22:53-67.

PULZ, F.A., SCOLFORO, J.R., OLIVEIRA, A.D., MELLO, J.M. \& OLIVEIRA FILHO, A.T. 1999. Acuracidade da predição da distribuição diamétrica de uma floresta inequiânea com a matriz de transição. Cerne 5:1-14.

RATTER, J.A. 1991. Guia para a vegetação da Fazenda Água Limpa (Brasília, DF): com uma chave para os gêneros lenhosos de dicotiledôneas do cerrado. Coleção Textos Universitários. Editora da Universidade de Brasília, Brasília. 
REATTO, A., CORREIA, J.R., SPERA, S.T. \& MARTINS, E.S. 2008. Solos do bioma Cerrado: aspectos pedológicos. In Cerrado: ecologia e flora. (S.M. Sano, S.P. Almeida \& J.F. Ribeiro, eds.). Embrapa Cerrados/Embrapa Informação Tecnológica, Brasília, v.1, p.106-150.

RIBEIRO, J.F. \& WALTER, B.M.T. 2008. As principais fitofisionomias do bioma Cerrado. In Cerrado: ecologia e flora. (S.M. Sano, S.P. Almeida \& J.F. Ribeiro, eds.). Embrapa Cerrados/Embrapa Informação Tecnológica, Brasília, v.1, p.151-199.

ROCHA, C.T.V., CARVALHO, D.A., FONTES, M.A.L, OLIVEIRA FILHO, A.T., VAN DEN BERG, E. \& MARQUES, J.J.G.S.M. 2005. Comunidade arbórea de um continuum entre floresta paludosa e de encosta em Coqueiral, Minas Gerais, Brasil. Revista Brasileira de Botânica 28:203-218.

SAMPAIO, A.B., WALTER, B.M.T. \& FELFILI, J.M. 2000. Diversidade e distribuição de espécies arbóreas em duas matas de galeria na micro-bacia do Riacho Fundo, Distrito Federal. Acta Botanica Brasilica 14:197-214.

SCOLFORO, J.R.S. \& MELLO, J.M. 2006. Inventário Florestal. Universidade de Lavras / Fundação de Apoio ao Ensino, Pesquisa e Extensão, Lavras.

SHEIL, D., BURSLEM, D.F.R.P. \& ALDER, D. 1995. The interpretation and misinterpretation of mortality rate measures. Journal of Ecology 83:331-333.

SILVA, A.C., VAN DEN BERG, E., HIGUCHI, P. \& OLIVEIRA FILHO, A.T. 2007. Comparação florística de florestas inundáveis das regiões sudeste e sul do Brasil. Revista Brasileira de Botânica 30:257-269.

SILVA JÚNIOR, M.C. 1998. Comunidades de árvores e sua relação com os solos na mata do Pitoco, Reserva Ecológica do IBGE, Brasília, DF. Revista Árvore 22: 29-40.

SILVA JÚNIOR, M.C. 2001. Comparação entre matas de galeria no Distrito Federal e a efetividade do Código Florestal na proteção de sua diversidade arbórea. Acta Botanica Brasilica 15:139-146.

SILVA JÚNIOR, M.C., FELFILI, J.M., WALTER, B.M.T., NOGUEIRA, P.E., REZENDE, A.V., MORAIS, R.O. \& NÓBREGA, M.G.G. 2001. Análise da flora arbórea de matas de galeria no Distrito Federal: 21 levantamentos. In Cerrado: caracterização e recuperação de matas de galeria. (J.F. Ribeiro, C.E.L. Fonseca \& J.C. SousaSilva, eds.). Planaltina, Embrapa Cerrados, p.143-191.
SILVERTOWN, J.W. \& DOUST, J.L. 1993. Introduction to plant population biology. Blackwell Scientific Publications, London.

SPIEGEL, M.P. 1976. Estatística. McGraw-Hill, São Paulo.

SWAINE, M.D. \& LIEBERMAN, D. 1987. Note on the calculation of mortality rates. Journal of Tropical Ecology 3:ii-iii.

SWAINE, M.D., LIEBERMAN, D. \& PUTZ, F.E. 1987. The dynamics of tree populations in tropical forest: a review. Journal of Tropical Ecology 3:359-366.

SWAINE, M.D. \& WHITMORE, T.C. 1988. On the definition of the ecological species groups in tropical rain forests. Vegetatio 75:81-86.

TEIXEIRA, A.P. \& ASSIS, M.A. 2005. Caracterização florística e fitossociológica do componente arbustivoarbóreo de uma floresta paludosa no município de Rio Claro (SP), Brasil. Revista Brasileira de Botânica 28:467-476.

TEIXEIRA, A.P., ASSIS, M.A., SIQUEIRA, F.R. \& CASAGRANDE, J.C. 2008. Tree species composition and environmental relationships in a Neotropical swamp forest in southeastern Brazil. Wetlands Ecology and Management 16:451-461.

TONIATO, M.T.Z., LEITÃO FILHO, H.F. \& RODRIGUES, R.R. 1998. Fitossociologia de um remanescente de floresta higrófila (mata de brejo) em Campinas, SP. Revista Brasileira de Botânica 21:197-210.

TORRES, R.B., MATTHES, L.A.F. \& RODRIGUES, R.R. 1994. Florística e estrutura do componente arbóreo de mata de brejo em Campinas, SP. Revista Brasileira de Botânica 17:189-194.

WALTER, B.M.T. 1995. Distribuição espacial de espécies perenes em uma mata de galeria inundável no Distrito Federal: florística e fitossociologia. Tese de mestrado, Universidade de Brasília, Brasília.

WALTER, B.M.T. \& RIBEIRO, J.F. 1997. Spatial floristic patterns in gallery forests in the Cerrado Region, Brazil. In International Symposium on Assessment and Monitoring of Forests in Tropical Dry Regions with Special Reference to Gallery Forests (J. Imaña-Encinas \& C. Kleinn, org.). University of Brasília, Brasília, p.339-349.

WALTER, B.M.T. \& SAMPAIO, A.B. 1998. A vegetação da Fazenda Sucupira. Embrapa Recursos Genéticos e Biotecnologia, Brasília. 